caustic soda in excess to a solution of copper sulphate and tartaric acid, with which has been mixed a little grape sugar (a small quantity of "set" honey): the formation of yellow cuprous oxide commences at the surface of the liquid, and is seen gradisally to extend to the lower parts, showing: hat the upper parts first attain the temperature requisite to cause the reacticn to occur which precipitates cuprous oxide.

These experiments are easy of execution, and by the above arrangement, or still better by being projected on the screen, may be rendered visible at a considerable distance.

Queenwood College

Frank Cíowes

\section{Mr. Garrod's Theory of Nerve-Force}

THE thermo-electric theory of nerve-force propounded by $\mathrm{Mr}$. Garrod (NATURE, vol. viii. p. 265) seems capable of extension. If a pole of metal, cased in a non-conducting sheath, were sunk in an artesian boring so as to reach from the level of constant temperature to the greatest depth attainable, how far wonld such pole fulfil the conditions of a sheathed nerve penetrating from the cool surface of an animal to the warmer interior? And with so litle difference of temperature in so great a length, would its dynamic effect be at all appreciable?

A quarter of a mile of submarine cable let down the shaft of oni Carnbrea mine might represent a sheathed nerve; and any existing nerve-force might there be tested. Abandoned mineshafts are the terrors of our Comish moorlands. Is it within the power of Science to convert them into earth-nerves, say by lining their sides with non-conducting material, and then packing them tight with conductive slag or some kind of metallic refuse? And is it possible, even in theory, to make such earthnerves work some kind of earth-muscle? For ignorant me to speak of this subject is ultracrepidism (NATURe, vol, vii. p. 262). Yet it seems a fair extension of Mr. Garrod's ingenious theory.

Carnbrea, Cornwall Augustine Chudieigh

\section{Genesis in Borneo}

Mr. CAMERoN's paper read at the Society of Biblical Archrology, testifies to the early diffusion of Semitic traditions by the agency, it may be inferred, of Moslem converts.

The same traditional coincidences recorded of Borneo are found in New Zealand and elsewhere, and would naturally ac. company the diffusion of Malayan dialects throughout Pulynesia, an influence the duration of which may be counted by centuries.

Dec. II

A. HALL

\section{Indian Snakes}

IN a small treatise on Indian snakes by Dr. Nicholson, R.A., the author states his belief that cobras will not feed in captivity unless forced to, starving themselves voluntarily to death. He thinks, also, that jugglers in this country either "feed their cobras with liquid nourishment, or else let them loose when their Iives are in danger,' recapturing them at a future time.

To test the correctness of this, I questioned a snake-charmer a few days ago, and he informed me that he fed his cobra every week with frogs. His snake had then been recently fed, so he weel the bungalow again in a few days. A frog ( $R$. tigrina) was procured, and placed in the small basket in which the cobra was kept. The latter seized it at once; but as I was anxious to see the whole process, which could not be done whilst the snake was coiled up in the basket, I requested the man to place the frog on the ground. As it struggled away (the hind limbs of the poor reptile had been broken) the cobra followed it eagerly, and again and again seized it. The want of fangs, and the size of the frog, which in its inflated state exceeded considerably the circumference of its enemy, rendered these attempts ineffectual; so a smaller frog was caught, and placed with the cobra in the basket. This was swa!lowed in a short time, the snake pushing its victim against its coils, and working down the hind limbs by a lateral motion of the lower jaw, very similar to that of a cow chewing the cud.

The large frog was now placed in the basket, and the cover put on, and in about half an hour had followed its companion. The cobra's appetite was now appeased, for after seizing a third frog it let it go, on its croaking a remonstrance.

A larghable incident occurred whilst the snake was following the frog over the gravel path. A performing monkey belonging to the jurgler, in a spin it of mischief, or perhaps fearing that its master's property was escaping, stepped gravely after the snake and laid hold of it by the tail. As a natural consequence, round came the cobra and menaced the monkey, which, retreating with sundry grimaces, took refuge with the juggler, in great alarm at the turn events had taken.

This cobra is a small one, and as it is one of those very pale, almost cream-coloured varieties, that finds no mention in Güinther's able work, I am anxious to examine it thoroughly. The owner, however, affirms that he has to draw its fangs about once a month, and as he is most cautious in handling the reptile, it is probable that the fang matrix has not been destroyed, and ex. amination will be safest just after the operation of extracting the fangs.

$$
\text { IVingalore, Sept. } 12
$$

E H. Pringle

\section{CLASSIFICATION OF CLOUDS*}

$\mathrm{N}$ an essay on the "Modifications of Clouds, read to 1 the Askesian Society in 1802 , Howard first proposed his classification of clouds, which has since been the generally recaived authority on the subject. His system has thus stood its ground for more than half a century, in spite of its defects and of the misconstruction not unfrequently put on the two terms, "stratus" and "nimbus" since the publication of Kaemtz's Meteorology. These misapprehensions and the obscurity and confusion arising from them are pointed out by Prof. Poey, but the errors have not been followed so generally as is asserted, at least by British meteorologists. In a series of papers issued at intervals during the past eleven years, Prof. Poey has endeavoured to develop a new classification of clouds, of which the volume before us is the result.

The following is Poey's classification compared with that of Howard:- -

Poey's Classification. HOW Cloud composed of First type: cirrus.

First type: cirrus Ispicules of Derived: fcirro-stratus.

cirrus
cirro-stratt:s $f$ ice.

Derived: $\left.\quad \begin{array}{l}\text { cirro-stratis } \\ \text { cirro-cumulus } \\ \text { pallio-cirrus }\end{array}\right\}$ ice. $\quad \begin{aligned} & \text { Second type : cumulus. } \\ & \text { Derived: }\end{aligned}$

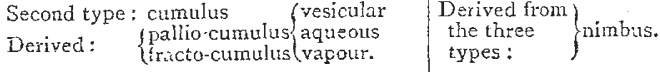

In forming his system, Prof. Poey first strikes out the "stratus" as being from Howard's own definition not a true cloud, but only "mist ;" the "cumulo-stratus" as not differing really from the cumulus; and the "nimbus" as beiog not a single cloud, but rather a system of clouds. He retains the word "stratus" as part-descriptive of the "cirro-stratus," but in this case it is exclusively restricted to those instances where the cirrus arranges itself in a stratified form, and is not applied when the arrangement is an extended sheet $\sigma_{\vec{x}}$ continuous layer of considerable thickness totally impervious to the sun's rays. To this latter condition, the new term "pallium" is applied.

In his classification Poey arranges the clouds in the order in which they severally appear, from the cirrus, the most elevated, its height being from 30,000 to 50,000 feet, to the fracto-cumulus, the lowest of all ; and groups them into three divisions according as they are composed of ice-crystals, snowy particles, or vesicular vapour.

But the most fundamental change which he has introduced into the system is the pallizm or shect-cloud, in its two distinct forms of pallio-cirrus, and palizo cumulus, according as it is formed from the cirrus or the cumulus. The pallum is the greyish, or ash-coloured cloud which overspreads the whole sky, and from wbich rain falls continualiy for hours or days together. On the approach. of rain the pallio-cirrus is formed by the rapid increase and thickening of the cirrus cownwards from the enormous

" "Nouvelle Classification des Nuages suivie d'Instructions pour servir ż l'Observation des Nuages et des Courants Atmospheriques; Par Andre (17 Planches).
(1) 
accessions of moisture that take place, by which this high ice-cold region of the atmosphere over a great extent and thickness, is brought to the point of saturation and condensation. Underneath this leaden-hued mass of cloud which uniformly covers the sky, but separated from it by a clear space, is extended the dense cloud covering of the pallio-cumulus, which is formed by the watery vapour of the atmosphere reduced to the points of condensation and precipitation. This is the true raincloud, and it is fed and increased by the rapid drifting in from below of torn masses of cumulus constituting the fracto-cumulus or wind-cloud. The fracto-cumulus may be of all sizes, has no determinate shape, is the lowest and swiftest moving of the clouds, and is whitish, greyish, or slate-coloured, as may be determined by the hygrometric condition of the air. On the return of fine weather accessions of vapour by the fracto-cumulus slacken and then cease, the pallio-cumulus diminishes in thickness and gradually clears away, showing through its intervals the pallio-cirrus above it, which in its turn is broken up, revealing still higher up the delicate tracery of the cirrus. The pallio-cirrus is negatively electrical, whitst the palliocumulus is positively electrical, the clear stratum between being neutral; and between these oppositely electrified strata, discharges frequently take place in thunderstorms.

The merits of Prof. Poey's work are very considerable, whether they be regarded as expository of Howard, or as a contribution to this difficult branch of meteorology; and it is just those meteorologists who have paid particular attention to the observation of the clouds who will be readiest to recognise its merits. It must, however, be conceded that, as a descripitive classification of clouds, as well as explanatory of the phenomena they present, Prof. Poey's work leaves the subject in a state still too incomplete to warrant us in recommending his system for general introduction. It is a step in the right direction, and will materially contribute to place this vitally important department of atmospheric physics on a satisfactory footing.

Toward this end, what is now urgently wanted is an extensive collection of the data of cloud-phenomena in all countries, particularly of those cloucls interesting in themselves or from their known relations to weather changes. We have more than enough of unmistakeably pure typical forms scattered through the pages of weather-literature, but such do not greatly assist us. in describing and classifying many of the forms of clouds which occur. Hence what is required is faithfully accurate delineations of these forms in their different aspects, and systematic inquiries set on foct into the relations of the forms of clouds to the mole of their formation, to the states of the aqueous vapour which compose them, and to the varying elasticity, temperature, and electricity of the atmosphere.

In connection with this part of the subject, Prof. Poey investigaied in $1862-64$, by means of the thermo-electric pile, the temperature of different parts of the sky under different conditions, and of the clouds which passed across it. Among other highly interesting results, he has shown that the cumulus, properly so called, and the cumulostratus of summer are the clouds of highest temperature; then follows the fracto-cumulus, except when it comes aiter the rain which accompanies a thunderstorm, in which case it is of a whitish colour, very rapid in its motion, much torn at the edges, and partakes of the low temperature prevailing on such occasions. The cirrocumulus is colder than the cumulus and the cirrus the coldest of all the clouds. These are very suggestive results. We are convinced that the key to the position in neteorology is a better knowledge of the vapour of the atmosphere in its various states and changes; and the science will not make the advances it is destined to make till meteorologists generally recognise the necessity of equipping their first-class observatories with the requisite appliances for carrying on those physical researches which are intimately allied to meteorology.

\section{FERTILISATION OF FLOWERS BY INSECTS} $\mathrm{V}$.

More conspicuous flowers adapted to cross-fertilisation, and less conspicuous ones adapted to self-fertilisation, occurring in different species of the same genus.

WHAT has been described in the two last articles as occurring in varieties of the same species (using the term "species" in its widest sense) we propose now to investigate as existing likewise in species of the same genus.

\section{Malva sylvestris and rotundifolia}

are two closely allied, but, as acknowledged by all botanists, undoubtedly good and distinct species, differing in their flowers in a manner similar to the two varieties of Lysimachia vulgaris and the other species previously considered. In both these species of Malva an oval mass of anthers in the first place occupies the middle of the flower, enclosing the stigmatic branches as yet undeveloped and lying close together (Fig. 23). At a later period the stigmatic branches, growing out of and overtopping the mass of anthers, spread and bend outwards and downwards so as to occupy nearly the same place as was before occupied by the anthers (Figs. 24, 25). Insects therefore, seeking for the honey which is secreted and contained in five cavities between the lowest parts of the petals (n, Fig. 23) and covered by a fringe of hairs (pr), carry away on their hairy bodies the large prickly pollengrains from younger flowers, leaving many of them on the stigmatic papillæ of the branches of the style of older flowers, which they can scarcely avoid grazing in seeking for the honey. Hence, in both species, whenever insects frequently visit these flowers, cross-fertilisation in the mannerdescribed is largely effected, whereas self-fertilisation can scarcely take place, neither spontaneously nor by means of insects, nearly ail the pollen-grains having been removed before the unfolding of the stigmatic branches. Since, however, Malva sylvestris and rotundifolia grow for the most part in the same locality, and flower during several months at the same time, insects flying about and seeking for honey are much more likely to find out and visit the highly conspicuous flowers of $M$. syluestris than the far less conspicuous ones of $M$. rotundifolia; the former, when fully opened, presenting bright rose-coloured bells of from 40 to $50 \mathrm{~mm}$. diameter, the latter, on the contrary, light rosecoloured bells of only from 20 to $25 \mathrm{~mm}$.

Direct observation, indeed, fully confirms this supposition, the flowers of $M$. sylvestris being always fourd in sunny weather visited by a variety of insects, whereas those of $M$. rotundifolia, especially when growing intermixed with $M$. syluestris, are commonly overlooked by them all. Thus, during the sixlast summers, I have observed on the flowers of $M$. sylvestris and collected more than 50 species of insecks, many of them very frequently ( 2 Lepidoptera, 3 Diptera, 5 Coleoptera, 40 Apidæ, some Ichneumonidx) ; while in the same space of time I found on the flowers of $M$. rotundifolia but 5 species (4 Apida, I Hemipter), and those only in single or a few cases.

It is evident from these facts, that wherever our two species of Malva grow together in the same locality, $M$. rotundifolia would be rapidly extinguished, unless it were enabled to produce seed by self-fertilisation; $M$. sylvesiris, on the other harid, is so commonly visited and cross-fertilised by insects that self-fertilisation, if it were possible, would never be effected, or only exceptionally. Accordingly natural selection must have preserved and accumulated those slight individual variations of $M$. rotundifclia, which afford facility for self-fertilisation, whereas in $M$. sylvestris the possibility of self-fertilisation being quite useless, might be lost, and, indeed, has been, completely or nearly lost. Thus in the flowers of $M$. sylvestris, when precluded from the visits of insects by covering them with 